\title{
Hyphoderma moniliforme and H. nemorale (Basidiomycota) newly recorded from China
}

\section{Yurchenko $\mathrm{E}^{1}$ and $\mathrm{Wu} \mathrm{SH}^{2}$}

${ }^{1}$ Department of Biotechnology, Paleski State University, Dnyaprouskai flatylii str. 23, BY-225710, Pinsk, Belarus; Email: eugene_yu@tut.by

${ }^{2}$ Department of Biology, National Museum of Natural Science, Taichung 404, Taiwan; Email: shwu@mail.nmns.edu.tw

Yurchenko E, Wu SH 2015 - Hyphoderma moniliforme and H. nemorale (Basidiomycota) newly recorded from China. Mycosphere 6(1), 113-121, Doi 10.5943/mycosphere/6/1/11

\begin{abstract}
Hyphoderma moniliforme and H. nemorale, saprobically growing on wood, are recorded as new for mycobiota of China. Both species were collected in mountains at the altitudes of 1850-3000 m, from Yunnan Province (southwestern China). Hyphoderma moniliforme is also a new record for Eurasia, and previously known only from South Africa. The collections of $H$. nemorale in this study represent the most eastern and the most southern localities for this species known for Eurasia. Both species bear moniliform cystidia. Bayesian inference of phylogeny based on ITS and partial 28S nuclear ribosomal DNA sequences indicated that $H$. moniliforme is united in one clade with $H$. litschaueri from North America. 28S-based phylogram demonstrated that Chinese $H$. nemorale belong to the same clade with the holotype of this species collected from Europe. Morphology descriptions and illustrations for these two species are provided.
\end{abstract}

Key words - corticioid fungi - Meruliaceae - Polyporales - taxonomy - wood-decay fungi

\section{Introduction}

Hyphoderma Wallr. (Meruliaceae, Polyporales) is one of the most species-rich and taxonomically complicated genera among corticioid fungi. The main generic features of this genus are effused basidiomata, broad subicular hyphae with relatively small clamp-connections (hyphae of 'hyphodermoid' morphology), typically large, subclavate basidia with a slight constriction at middle, and inamyloid basidiospores, which in most species are median-large, cylindrical and thinwalled. According to phylogenetic evidence, Larsson (2007) treated most species of Hyphoderma s. 1. as the genera Hyphoderma s. str. and Peniophorella P. Karst.

According to the list of Dai (2011), 14 species, now belonging to Hyphoderma s. str., were recorded in mycobiota of the whole China. The present paper adds two new species of Hyphoderma s. str. based on the material collected from Yunnan Province of China.

\section{Materials \& Methods}

\section{Collections and morphology study}

Herbarium specimens were collected in Yunnan Province by S.H. Wu in 1995 and 2002, and deposited in TNM; duplicates were deposited in MSK (herbarium acronyms follow Index Herbariorum, http://sweetgum.nybg.org/ih). Isolates are kept in culture collection at TNM. 
Descriptions of macromorphology were based on dry basidiomata. Microscopic measurements and drawings were done from the material mounted in $3 \% \mathrm{KOH}$ water solution. Crystalline incrustations on hyphae, cystidia, and basidia, and spore wall amyloid or dextrinoid reaction were studied in Melzer's reagent. Sporal wall cyanophily was tested in cotton bluelactophenol solution.

\section{DNA extraction, amplification, and sequencing}

In addition to morphological data, nuclear ribosomal DNA sequences were obtained to clarify taxonomic placement of the specimens. The materials for DNA isolation were the mycelia grown in pure culture ( $W u$ 0211-42, Wu 0211-46, Wu 9508-14) or fragments of the basidioma (TNM F3931). DNA was extracted with Plant Genomic DNA Extraction Miniprep Kit (Viogene, Taiwan), according to manufacturer's protocol. Primer pair ITS1/ITS4 was used for amplification of internal transcribed spacer region, including ITS1, 5.8S and ITS2. DNA fragment at the beginning of ribosomal large subunit gene (28S), was amplified with primer pair LR0R/LR5. Amplifications were run on Mastercycler Gradient 5331 thermal cycler (Eppendorf, Germany). Amplification products were purified with PCR-M Clean Up kit (Viogene) and sequenced with ABI PRISM BigDye Terminator Cycle Sequencing Ready Reaction kit on ABI 3730 DNA sequencer (Applied Biosystems, USA). The original sequences were deposited in NCBI GenBank (Table 1).

Table 1 Data on species, specimens, and their sequences used in phylogenetic analysis.

\begin{tabular}{|c|c|c|c|c|}
\hline \multirow{2}{*}{ Species name } & \multirow{2}{*}{$\begin{array}{c}\text { Isolate / } \\
\text { Specimen voucher }\end{array}$} & \multirow{2}{*}{$\begin{array}{l}\text { Contry } \\
\text { of origin }\end{array}$} & \multicolumn{2}{|c|}{$\begin{array}{c}\text { GenBank accession no. } \\
\text { for nrDNA }\end{array}$} \\
\hline & & & $\begin{array}{l}\text { ITS1-5.8S- } \\
\text { ITS2 }\end{array}$ & $28 S$ \\
\hline Hyphoderma cremeoalbum & FCUG 2270 / NH 11538 (GB) & Turkey & - & DQ677492 \\
\hline Hyphoderma definitum & FCUG 2426 / NH 12266 & $\begin{array}{l}\text { Russia } \\
\text { (Krasnodar krai) }\end{array}$ & AJ534293 & - \\
\hline Hyphoderma granuliferum & / KHL $12561(\mathrm{O})$ & Costa Rica & JN710545 & - \\
\hline Hyphoderma incrustatum & FCUG 2029 / KHL 6685 & Sweden & - & AY586668 \\
\hline Hyphoderma litschaueri & / CFMR:DLL2011-050 & USA & KJ140573 & - \\
\hline Hyphoderma litschaueri & FCUG 786 / NH 7603 (GB) & Canada & - & DQ677496 \\
\hline Hyphoderma macaronesicum & E09/57-9 / TFC:Mic.15981 & Canary Islands & HE577027 & - \\
\hline Hyphoderma macaronesicum & E06/61-10 / MA:Fungi:16099Tell & Azores & HE577028 & - \\
\hline Hyphoderma medioburiense & FCUG 2113 / NH 10950 (GB) & Spain & - & DQ677497 \\
\hline Hyphoderma moniliforme $*$ & Wu 0211-42 / TNM F14735 & China & КC928282 & КС928283 \\
\hline Hyphoderma moniliforme & Wu 0211-46 / TNM F14739 & China & КC928284 & KC928285 \\
\hline Hyphoderma nemorale & Wu 9508-14 / TNM F3910 & China & КС928280 & КC928281 \\
\hline Hyphoderma nemorale & / TNM F3931 & China & KJ885183 & KJ885184 \\
\hline Hyphoderma nemorale & FCUG 2324 / EM 2793 & Switzerland & - & AY586669 \\
\hline Hyphoderma nudicephalum & / TMIC 30479 & Japan & AJ534267 & - \\
\hline Hyphoderma nudicephalum & $\mathrm{Wu} 9508-225$ / & China & AJ534268 & - \\
\hline Hyphoderma obtusum & / JS 17804 & Norway & - & AY586670 \\
\hline Hyphoderma occidentale & / KHL 8469G (GB) & Sweden & - & AY586674 \\
\hline Hyphoderma occidentale & / KHL 8477 (GB) & Sweden & - & DQ677499 \\
\hline Hyphoderma prosopidis & E09/58-9 / ARIZ:H.H. Burdsall 8479 & USA & HE577029 & - \\
\hline Hyphoderma roseocremeum & FCUG 1945 / NH 10545 & Denmark & - & AY586672 \\
\hline Hyphoderma setigerum & / GEL 4001 & Germany & - & AJ406511 \\
\hline Hyphoderma setigerum & FCUG 1264 / NH 8544 (GB) & Sweden & - & FN907905 \\
\hline Hyphoderma setigerum & CFMR:HHB2578 / & USA & GQ409523 & - \\
\hline Hyphoderma setigerum & CFMR:FP150263 / & Jamaica & GQ409528 & - \\
\hline Hyphoderma setigerum & / CFMR:DLL2011-267 & USA & $\mathrm{KJ} 140750$ & - \\
\hline Hyphoderma subsetigerum & Wu 9508-155/ & China & AJ534275 & - \\
\hline Mutatoderma heterocystidium** & FCUG 780/2 / NH 7574 (GB) & Canada & - & DQ677495 \\
\hline Mutatoderma mutatum & FCUG 2403 / NH 12026 (GB) & Russia & - & DQ677498 \\
\hline Phanerochaete sordida & / KHL 12054 (GB) & Norway & EU118653 & EU118653 \\
\hline
\end{tabular}

*Data in bold belong to the sequences obtained in this study; **under the name Hyphoderma heterocystidiatum in GenBank 


\section{Sequence alignment and reconstruction of phylogeny}

The datasets were composed of both the sequences obtained in this study and extracted from GenBank (Tab. 1). The sequences, most similar to specimens of Hyphoderma from Yunnan, traced by BLAST and belonged to Hyphoderma and Mutatoderma (Parmasto) C.E. Gómez, were selected for ITS and 28S datasets. Phanerochaete sordida, from a sister clade to Meruliaceae (Larsson 2007), was assigned as the outgroup in both datasets. Sequences were aligned in MAFFT v. 7 at the web server (http://mafft.cbrc.jp/alignment/server), using E-INS-i strategy for ITS and G-INS-i strategy for 28S (Katoh et al. 2009). Before alignment, sequences were arranged in such the way that presumably more related taxa were dispersed among less related. Too long 3' and 5' protruding ends in sequences were cut before the final alignment. Aligned datasets were edited manually in MEGA v. 3.1 software (Kumar et al. 2004). Ready datasets and the resulting phylograms were deposited in TreeBASE (http://purl.org/phylo/treebase/phylows/study/TB2:S16138). The best-fit models of nucleotide evolution were estimated by MrModeltest v. 2.3 (https://www.abc.se/ nylander/mrmodeltest2/mrmodeltest2.html), using Akaike Information Criterion.

Bayesian analysis of phylogeny was performed in MrBayes v. 3.2.1 (Ronquist \& Huelsenbeck 2003). Both ITS and 28S datasets were individually analyzed using two independent runs, each with four $\mathrm{MC}^{3}$ chains running for 500000 generations, with tree and parameter sampling every 500 generations. Burn-in discarded $25 \%$ of samples. The ITS datamatrix was analysed with different parameter set for the two partitions, 5.8S and ITS1+ITS2, according to the best-fit models.

\section{Results}

\section{Species descriptions}

Hyphoderma moniliforme (P.H.B. Talbot) Manjón, G. Moreno \& Hjortstam, Mycotaxon 33: 261 (1988).

Figs $1-11$

Basidiomata effused, with age broadly cracking. Hymenophore smooth, milk white or creamish. Hyphae clamped at all primary septa, colorless. Subicular hyphae loosely arranged, sparsely branched, disordered (except thin layer of horizontal hyphae next to the substratum), (2.5-)3-5.5 $\mu \mathrm{m}$ diam, naked, with thin to thickened walls. Subhymenium thickening, compact, of thin-walled, naked or slightly encrusted hyphae 3.5-4 $\mu \mathrm{m}$ diam. Cystidia enclosed, 50-80 × 6$8 \mu \mathrm{m}$, moniliform in general or apically moniliform, thin-walled, colorless. Basidia clavatesubcylindrical, slightly median-constricted, 20-38 $\times 6-7.5(-8) \mu \mathrm{m}$, colorless, thin-walled, with four large sterigmata. Basidiospores oblong to cylindrical, $(7.5-) 8-9(-9.5) \times(3.2-) 3.5-4 \mu \mathrm{m}$, thinwalled, colorless, inamyloid, indextrinoid, with small or idistinct apiculus.
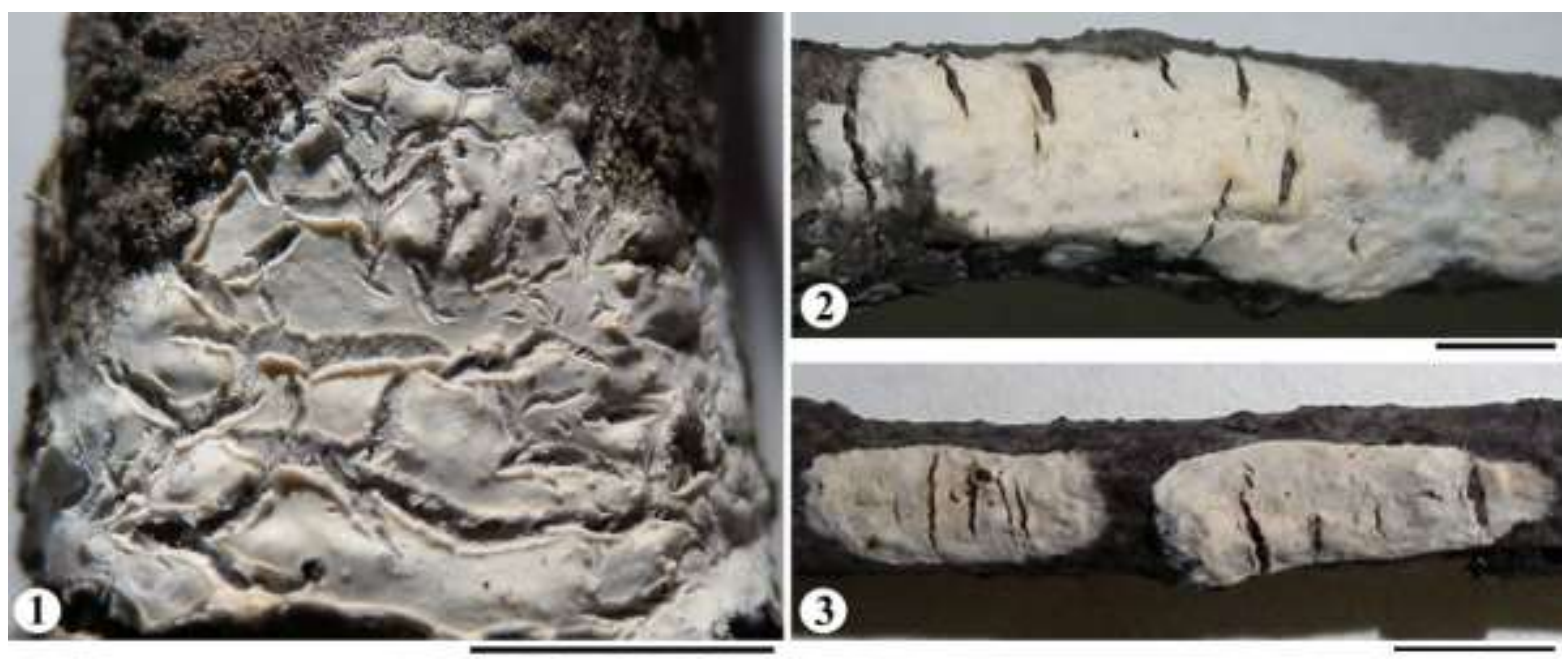

Figs 1-3 - Macromorphology of Hyphoderma moniliforme. 1 TNM F14732. 2 TNM F14735. 3 TNM F14739. Bars $=1 \mathrm{~cm}$. 


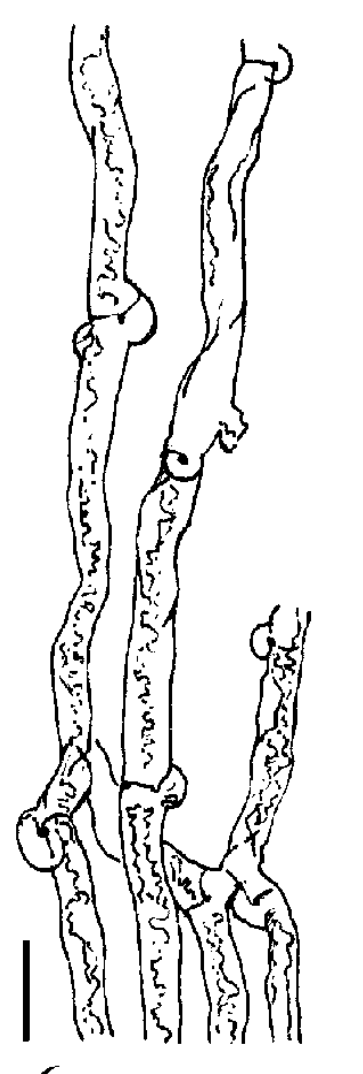

6
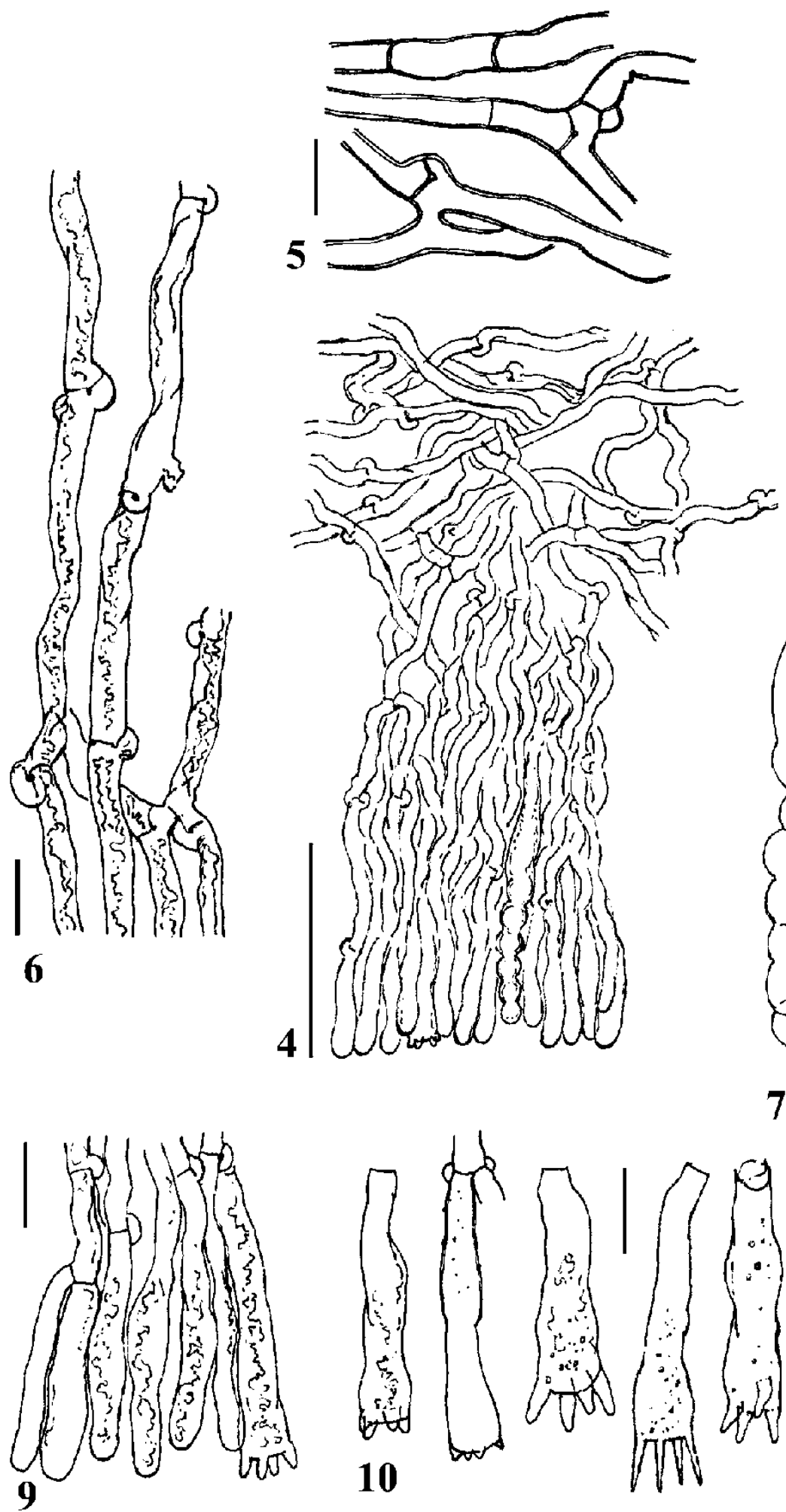
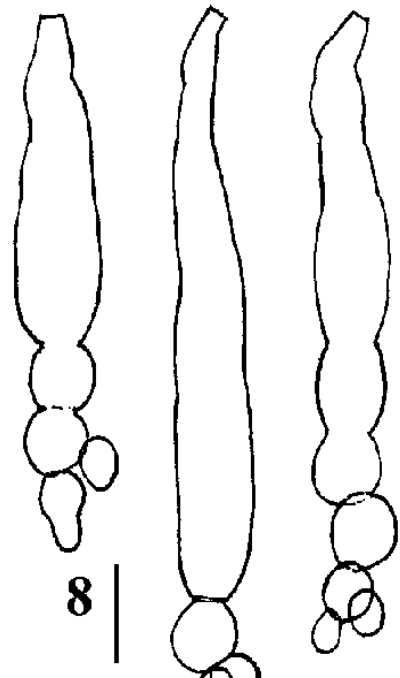

$\infty$
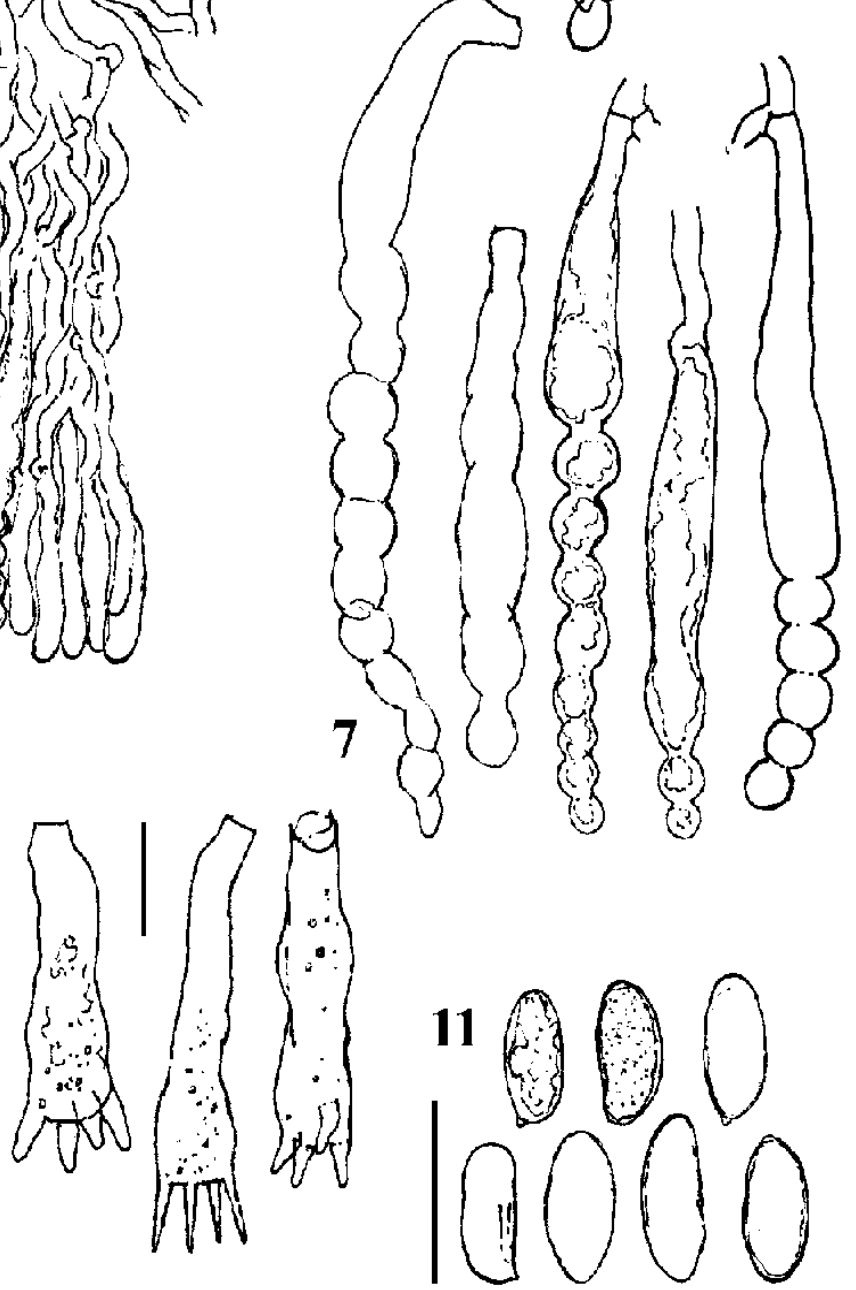

Figs 4-11 - Micromorphology of Hyphoderma moniliforme (TNM F14732). 4 Vertical section through basidioma. 5, 6 Subicular hyphae. 7 Unbranched cystidia. 8 Branched cystidia. 9 Portion of hymenium. 10 Basidia. 11 Basidiospores. Bars: for $4=50 \mu \mathrm{m}$, for $5-11=10 \mu \mathrm{m}$.

Material examined - China, Yunnan Province, Kunming, Chinlunghsia, alt. $1850 \mathrm{~m}$, 7 Nov 2002, S.H. Wu, Wu 0211-32 (TNM F14732, dup. in MSK); Chuhsiung, Tzuhsishan, alt. 2250 m, 8 Nov 2002, S.H. Wu, Wu 0211-42 (TNM F14735), alt. 2400 m, 9 Nov 2002, S.H. Wu, Wu 0211-46 (TNM F14739). All collections are from dead corticated branches of unidentified angiosperms. 
Basidiomata effused, soft-membranaceous or subpellicular, 90-180 $\mu \mathrm{m}$ thick. Hymenial surface colliculose, cream, when young minutely porulose, then almost continuous and slightly cracking. Margin farinaceous, paler colored, up to $2.5 \mathrm{~mm}$ broad. Hyphal system monomitic, hyphae clamped at all primary septa, moderately branched, 2.5-4 $\mu \mathrm{m}$ wide, colorless, thin- or almost thin-walled, naked to richly encrusted. Subiculum of loosely arranged, disordered or subvertical hyphae, richly interspersed by middle-sized crystalline material. Subhymenium not clearly differentiated. Cystidia scattered, subcylindrical to somewhat moniliform and capitate, slightly projecting, 35-70 $\times 7-8 \mu \mathrm{m}$, aseptate of with several (up to 5) adventitious septa, colorless, thin-walled, naked or somewhat encrusted basally; cystidioles numerous, suburniform to subcylindrical, often slightly capitate, a little protruding, 20-35 $\times 4-8 \mu \mathrm{m}$, colorless, thin-walled, more or less encrusted, with capitate apex 3.5-4.5(-5.5) $\mu \mathrm{m}$ broad. Basidioles slightly to richly encrusted mostly in lower and middle part. Basidia clamped at base, clavate or subclavate, slightly median constricted, 20-30 $\times 6.5-9.5 \mu \mathrm{m}$, thin-walled, more or less encrusted in lower and middle part, unicellular or with 1-3 adventitious septa, with 2-4 conical sterigmata $4-5 \times 1.3-1.5 \mu \mathrm{m}$. Spores cylindrical, adaxially slightly convex, flat, or somewhat depressed, (8.5-)9.5-14(-15) $\times$ (3.5-)4-5(-6) $\mu \mathrm{m}$, colorless or almost so, thin-walled, smooth; contents more or less granular or large-guttulate; wall negative in Melzer's reagent, slightly cyanophilous; apiculus very short or unclear.

Material examined - China, Yunnan Province, Lijiang, Santaowan, alt. 3000 m, 1 Aug 1995, S.H. Wu \& J.Y. Tseng, Wu 9508-14 (TNM F3910; dup. in MSK), Wu 9508-43 (TNM F3931). Both specimens were collected from dead twigs and branches of unidentified angiosperms.

\section{Molecular phylogeny}

The aligned ITS dataset which was undergone by Bayesian analysis included 624 positions, 418 of which were constant. MrModeltest suggested GTR+G as the best-fit model of nucleotide evolution for ITS1+ITS2, and $\mathrm{K} 80$ for $5.8 \mathrm{~S}$. The aligned datamatrix of partial $28 \mathrm{~S}$ sequences included 887 positions, 866 of which were constant. The best-fit model of nucleotide evolution suggested for it by MrModeltest was GTR+I+G.
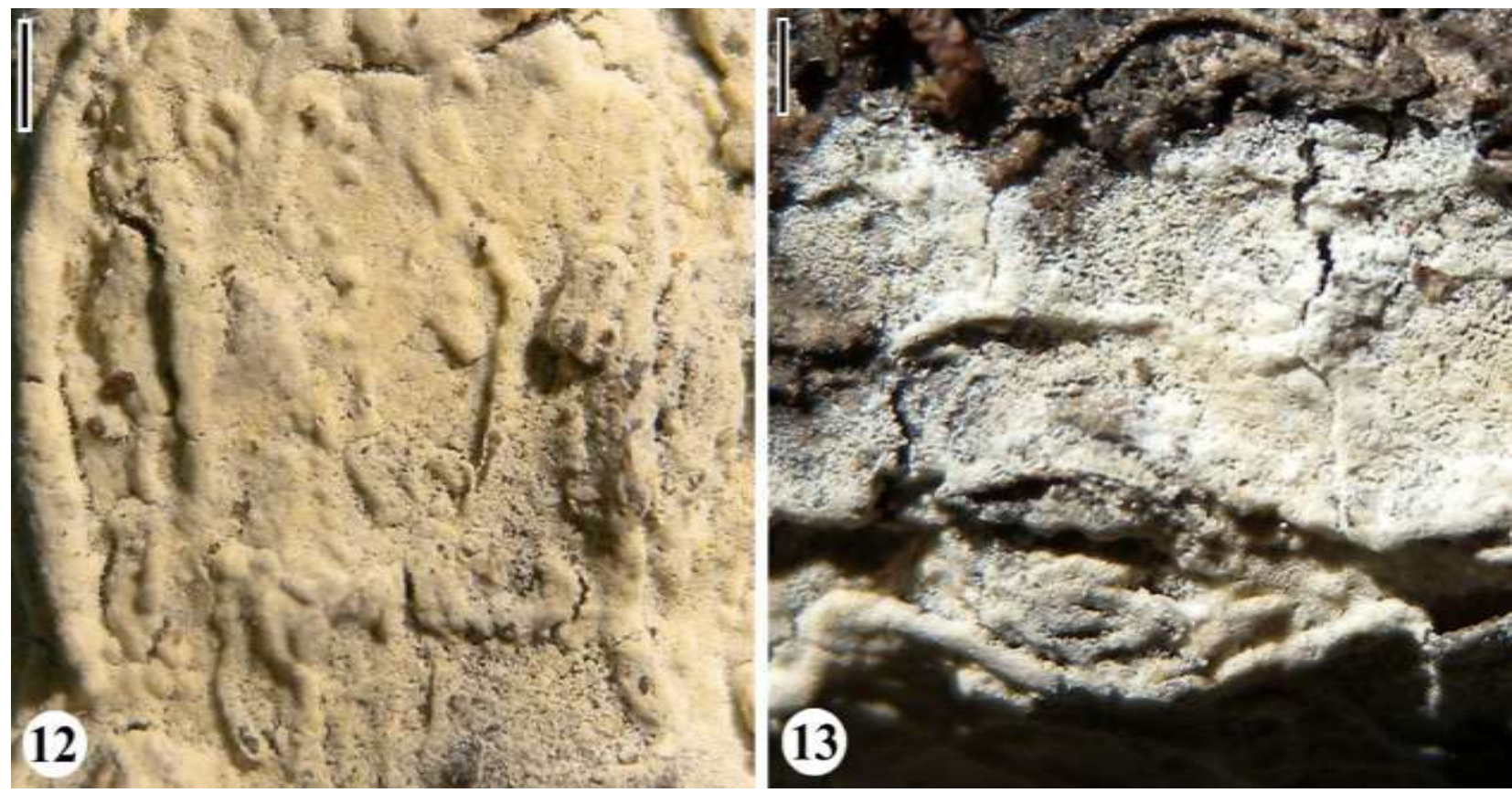

Figs 12-13 Macromorphology of Hyphoderma nemorale (TNM F3910). 12 Basidioma in central part. 13 Basidioma in marginal part. Bars $=1 \mathrm{~mm}$. 


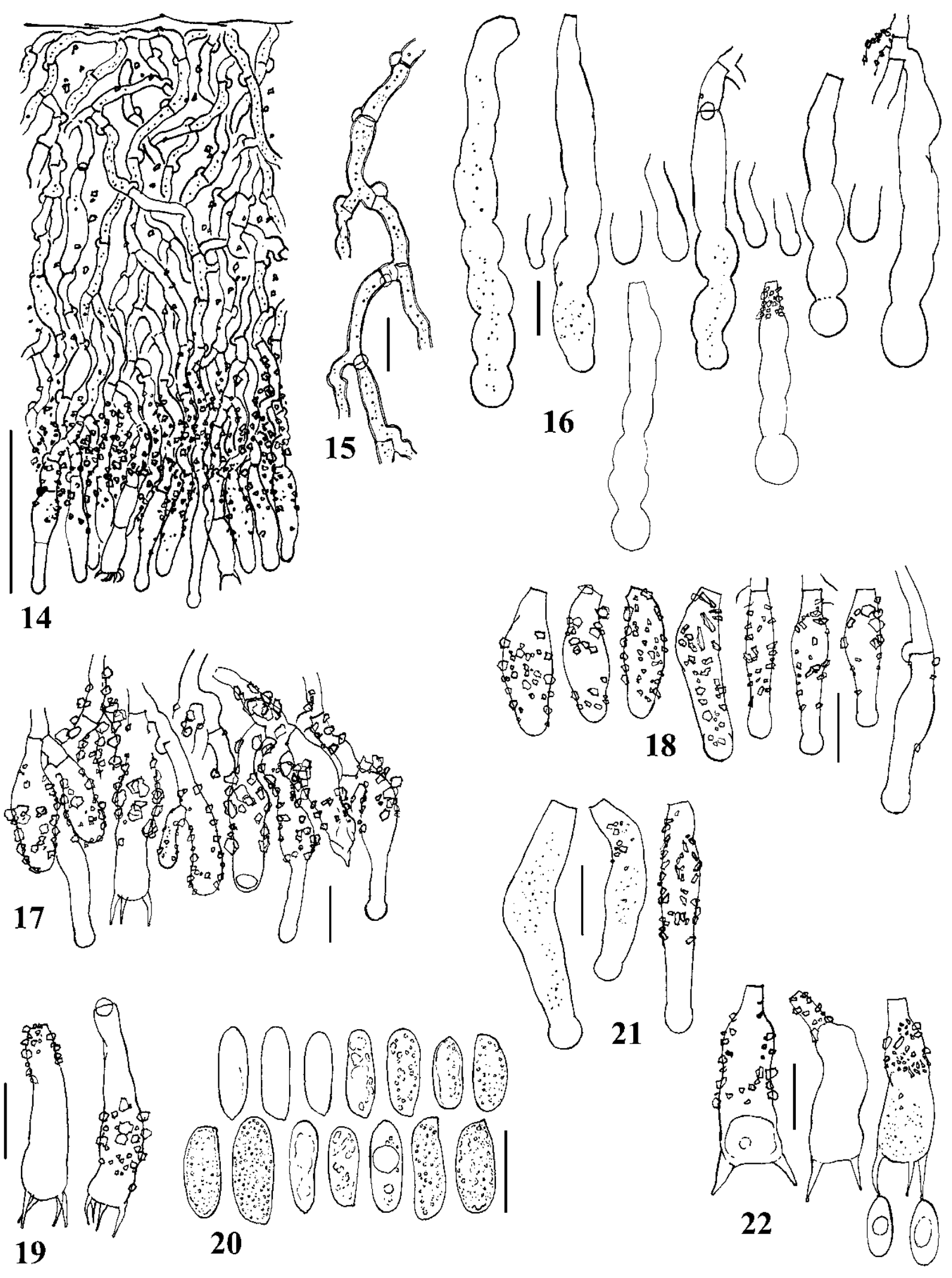

Figs 14-22 Micromorphology of Hyphoderma nemorale. 14-20 TNM F3910. 14 Vertical section through basidioma. 15 Subicular hyphae. 16 Submoniliform cystidia. 17 Portion of hymenium. 18 Basidioles (left) and subcapitate cystidioles (right). 19 Basidia. 20 Spores. 21, 22 TNM F3931. 21 Capitate cystidia. 22 Basidia. Bars: for $14=50 \mu \mathrm{m}$, for $15-22=10 \mu \mathrm{m}$. 

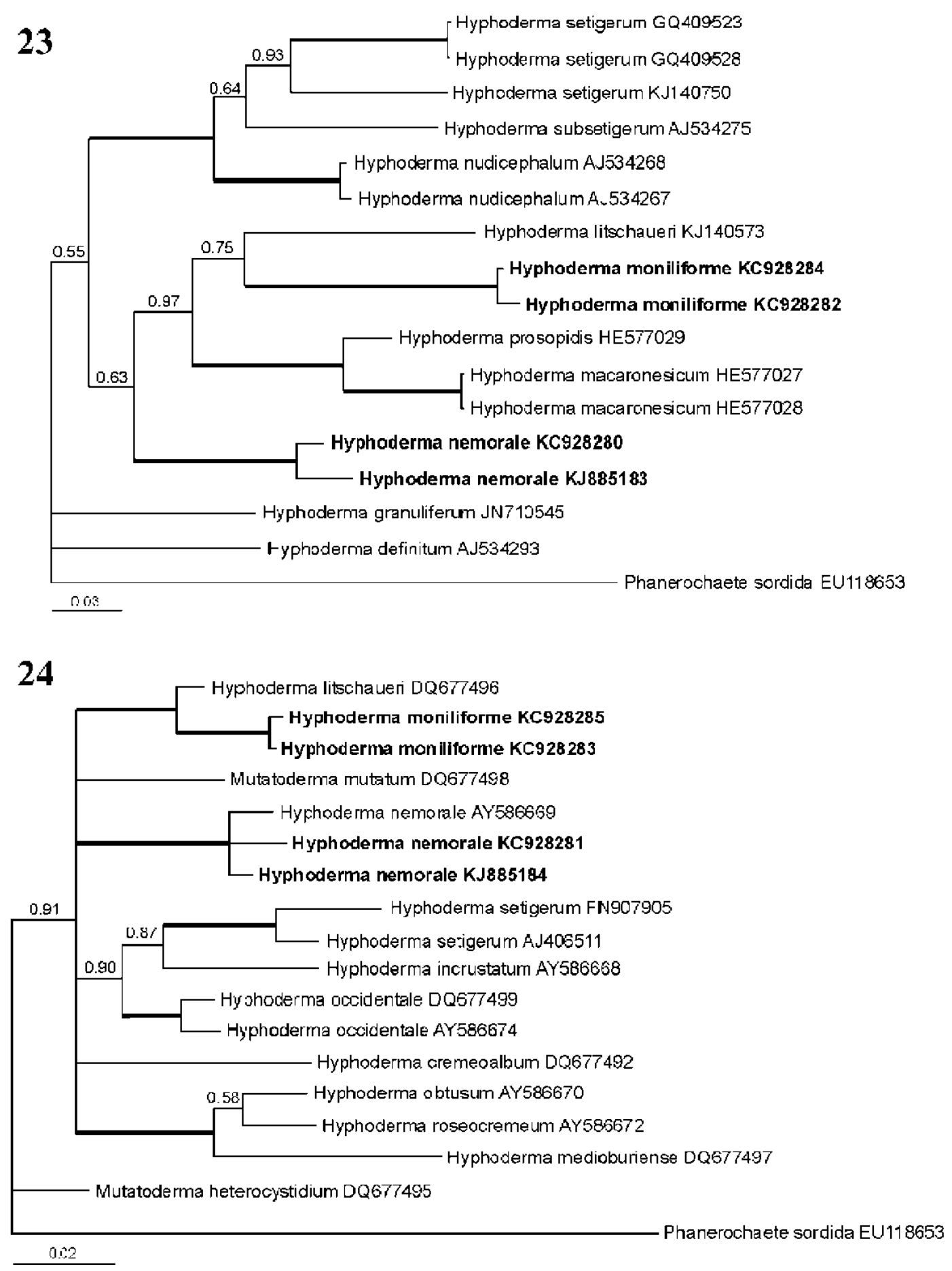

Figs 23-24 Consensus Bayesian phylograms for Hyphoderma species. 23 Based on ITS dataset. 24 Based on partial 28S dataset. Numbers above branches denote Bayesian posterior probability value $(\mathrm{PP})$. Thick branches have $\mathrm{PP}=0.99-1.00$. Bars: number of substitutions per site.

Both phylograms generated using Bayesian approach (Figs 23, 24) confirmed that the considered specimens from Yunnan belong to the genus Hyphoderma. The branch pattern on both phylograms demonstrates that specimens of $H$. moniliforme TNM F14735 and TNM F14739 have little molecular divergence and belong to the same independent species. Phylogenetic distances between two $H$. nemorale specimens, TNM F3910 and TNM F3931, suggest that they are also conspecific, but molecular divergence between them is fairly high in comparison with other Hyphoderma species. On the phylogram based on partial 28S sequences these two specimens occurred to be joint together in a highly supported clade (Bayesian posterior probability value, $\mathrm{PP}=$ 1.00) with the holotype of $H$. nemorale. 


\section{Discussion}

Characteristics of three studied specimens of $H$. moniliforme from Yunnan correspond with the description of Corticium moniliforme P.H.B. Talbot (Talbot 1958), except non-stratified context, shorter and somewhat narrower cystidia, and hyphal morphology. In Chinese specimens hyphae are fairly regular, while in $C$. moniliforme hyphae were described as tortuous and nodulose swollen. Our specimens differ from the similar species H. litschaueri (Burt) J. Erikss. \& A. Strid (Eriksson and Ryvarden 1975) by having non-porulose basidioma, longer and wider basidia, shorter and non-guttulate basidiospores. Moreover, in H. litschaueri the constrictions of cystidia are less pronounced. In $\mathrm{H}$. moniliforme the constricted part of cystidia has a tendency to be as if composed of a chain of globose cells. The specimens of $H$. moniliforme were collected in central part of Yunnan Province of China. Previous record of this species was only in South Africa (Talbot 1958).

Bayesian analyses of phylogeny based on ITS and 28S sequences (Figs 23, 24) demonstrated that $H$. moniliforme belongs to $H$. litschaueri-clade. This clade gets high posterior probability support $(\mathrm{PP}=1.00)$ in $28 \mathrm{~S}$-based phylogram. Both species in the clade have constricted cystidia. In the same time, in terms of molecular phylogeny H. moniliforme is well distinguished from North American specimen of $H$. litschaueri.

The specimens of $H$. nemorale from Yunnan fairly fit the type description of this species (Larsson 1998), except bearing shorter submoniliform cystidia and presence of incrustations on hyphae and hymenial elements. No incrustations in hymenium were noted in a description of $H$. nemorale from Asia (Ghobad-Nejhad et al. 2008). Richly encrusted basidia and incrustations in subhymenium in $H$. nemorale were decribed and illustrated based on Italian material (Bernicchia and Gorjón 2010). However, the authors noted that the hiatus between Italian specimens of $H$. nemorale and H. incrustatum K.H. Larss. is not distinct. The phylogenetic data reveal that the material from China is a form of $H$. nemorale with encrusted hymenium and subhymenium.

Hyphoderma nemorale was collected in northwest part of Yunnan Province, from temperate forest montane belt. Larsson (1998) supposed that $H$. nemorale is not rare in boreal and nemoral zones of Eurasia. This species was reported from Britain, Norway, Sweden, Finland, Denmark, Germany, France, Switzerland, Spain, Italy, Ukraine, Russia (Arkhangel'sk, Yamal, and Karachayevo-Cherkessiya), Cyprus, Iran (Larsson 1998, Ghobad-Nejhad et al. 2009, Bernicchia \& Gorjón 2010, Torrejón 2013). Ghobad-Nejhad et al. (2008) reported this species in NW Iran at the altitudes 1000-1800 m. The studied collections from Yunnan represent the most southern and the most eastern distribution locality known for this species.

Hyphoderma granuliferum P. Roberts (Roberts 2000) and H. incrustatum (Larsson 1998, Dämon 2000) also bear incrusted hymenial elements and more or less capitate cystidia. However, no close phylogenetic proximity among $H$. nemorale, $H$. granuliferum and $H$. incrustatum was demonstrated in the analyses (Figs 23, 24).

\section{Acknowledgements}

The research was supported financially by National Science Council of Taiwan (grants NSC 98-2621-B-178-002-MY3 and NSC 101-2621-B-178-001-MY3). Our thanks go to S.Z. Chen (TNM) for the help in managing herbarium specimens for this study, and to Y.P. Chen for performing DNA extraction and amplification.

\section{References}

Bernicchia A, Gorjón SP. 2010 - Corticiaceae s.l. (Fungi Europaei). Edizioni Candusso.

Dai YC. 2011 - A revised checklist of corticioid and hydnoid fungi in China for 2010. Mycoscience $52,69-79$.

Dämon W. 2000 - Corticioide Basidienpilze Österreichs 3. Österreichische Zeitschrift für Pilzkunde 9, 191-227.

Eriksson J, Ryvarden L. 1975 - The Corticiaceae of North Europe. Vol. 3: Coronicium Hyphoderma. Fungiflora, Oslo. 
Ghobad-Nejhad M, Hallenberg N, Kotiranta H. 2008 - Additions to the corticioids of the Caucasus from NW Iran. Mycotaxon 105, 269-293.

Ghobad-Nejhad M, Hallenberg N, Parmasto E, Kotiranta H. 2009 - A first annotated checklist of corticioid and polypore basidiomycetes of the Caucasus region. Mycologia Balcanica 6, 123 168.

Katoh K, Asimenos G, Toh H. 2009. Multiple alignment of DNA sequences with MAFFT. Methods in Molecular Biology 537, 39-64.

Kumar S, Tamura K, Nei M. 2004 - MEGA3: integrated software for Molecular Evolutionary Genetics Analysis and sequence alignment. Briefings in Bioinformatics 5, 150-163.

Larsson KH. 1998 - Two new species in Hyphoderma. Nordic Journal of Botany 18, 121-127.

Larsson KH. 2007 - Re-thinking the classification of corticioid fungi. Mycological Research 111, $1040-1063$.

Roberts P. 2000 - Corticioid fungi from Korup National Park, Cameroon. Kew Bulletin 55, 803-842.

Ronquist F, Huelsenbeck JP. 2003 - MrBayes 3: Bayesian phylogenetic inference under mixed models. Bioinformatics 19, 1572-1574.

Talbot PHB. 1958 - Studies on some South African resupinate Hymenomycetes. Part II. Bothalia 7, 131-187.

Torrejón M. 2013 - Fungi of Cyprus: new data on micro- and macrofungi. Acta Mycologica 48, 207-218. 